\title{
COMPARING THE USAGE DATA OF AN APP AND A MOBILE WEBSITE FOR AN ACADEMIC LIBRARY
}

\section{Comparación de los datos de uso de la app y el sitio web móvil de una biblioteca universitaria}

\author{
Natalia Arroyo-Vázquez and José-Antonio Merlo-Vega
}

Nota: Este artículo se puede leer en español en:

https://recyt.fecyt.es/index.php/EPI/article/view/61031

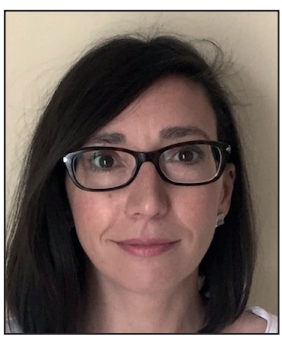

Natalia Arroyo-Vázquez holds a PhD on Library Science. Her research focuses on social media and mobile technology in libraries. She works as a librarian at the Universidad de Navarra (Spain). She has authored several books, book chapters, and papers about social media and mobile technology in libraries. She has actively participated in several conferences as a speaker and as a member of scientific committees. She is member of the think tank ThinkEPI Group.

http://orcid.org/0000-0002-4692-3420

natalia.arroyo@gmail.com

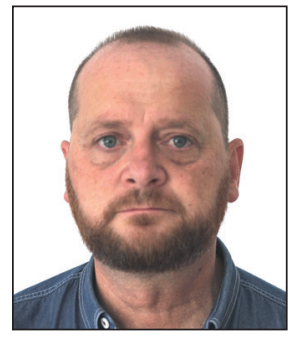

José-Antonio Merlo-Vega has a PhD on Library Science. He is a full professor and the director of the Library and Information Department at University of Salamanca. He is a regular teaching collaborator in several Mexican universities. He is an instructor of undergraduate and graduate courses in Information and Documentation and on Translation and Interpreting. His research is focused on libraries, electronic resources, open access, and applied technologies.

http://orcid.org/0000-0002-9102-4408

Universidad de Salamanca, Facultad de Traducción y Documentación Departamento de Biblioteconomía y Documentación Francisco de Vitoria, 6-16. 37008 Salamanca, Spain merlo@usal.es

\begin{abstract}
Apps are used by university libraries to disseminate their collections and services. In 2011 the University of Salamanca (USAL) launched the first mobile app for libraries in Spanish-speaking regions: Biblio USAL. Usage data was gathered for this app (2011-2015) and analyzed and compared to that of the university library's mobile website. The findings show a preference for adapted web versions and the need to offer new generation apps that provide services not featured on the website.
\end{abstract}

\section{Keywords}

Apps; Mobile web; Smartphones; Tablets; Academic libraries; User studies; University of Salamanca.

\section{Resumen}

Las bibliotecas universitarias emplean apps para la difusión de sus colecciones y servicios. La Universidad de Salamanca (USAL) lanzó en 2011 la primera aplicación de bibliotecas en el ámbito hispanohablante. Se analizan los datos de uso de la app BiblioUSAL (2011-2015) y se comparan con los datos de acceso a la versión móvil de su sitio web. El estudio determina la preferencia del usuario por las versiones web adaptadas y la necesidad de ofrecer apps de nueva generación que aporten servicios no disponibles en la web.

\section{Palabras clave}

Apps; Web móvil; Smartphones; Tabletas; Bibliotecas universitarias; Estudios de usuarios; Universidad de Salamanca.

Arroyo-Vázquez, Natalia; Merlo-Vega, José-Antonio (2017). “Comparing the usage data of an app and a mobile website for an academic library". El profesional de la información, v. 26, n. 6, pp. 1119-1126.

https://doi.org/10.3145/epi.2017.nov.11 


\section{Libraries, apps, and the mobile web: bibliographical review}

Mobile applications, commonly known as "apps", provided a new way to deliver content and services to users' smartphones and tablets in July 2008 via Apple's App Store. Apps are programs that enhance the features of a mobile device once they are installed. Apps should not be confused with web applications or software applications: web applications must be hosted by a server and accessed via an Internet browser, and software applications are installed on desktop PCs and/or laptops.

Libraries have been developing their own mobile applications in order to take advantage of the ubiquitous use of app stores. The first app ever released by a library was developed for the District of Columbia Public Library (USA) and was launched on January 8, 2009 (Bridges; Rempel; Griggs, 2010). Since then, a wealth of library apps have proliferated in online stores. The majority of these library apps reproduce the same content and services featured on the corresponding library's mobile website and mostly include informative content. But there are also apps which feature other utilities that aim to popularize libraries' historical collections, to access the catalog or including games (Arroyo-Vázquez, 2015).

A mobile website is an adapted version of the original website to be browsed on handheld mobile devices, such as smartphones. It is a separate version of the desktop website designed to be used exclusively on smartphone devices. It could be either an entirely different web page or created using responsive web design.

A pressing question in need of an answer is which option would be more satisfactory for the users of mobile devices: a mobile version of the website or an app. Several authors within the library world have addressed this matter before, mainly by reiterating arguments held in web development circles. First, the universal character of a website makes it easier to create and access on any browser, whereas an app can only be accessed on a device running on a certain operating system (Clark, 2012; Haefele, 2013; Serrano, 2014). Second, apps integrate better into the mobile device environment, thereby improving usability (Nielsen; Budiu, 2012). Third, it is only possible to take advantage of some features of the mobile device when using an app.

Otherwise, Wisniewski (2011) compares the matter of access between web applications and apps: the user must remember the website's URL, open a browser, enter the address, and wait for the page to load; the developer doesn't intervene in this process. However, when using an app all a user needs to do is tap. Nevertheless, this argument neglects the fact that the app must have previously been installed, which requires an action from the user. In addition, people browse directly through search engines, avoiding the need to type in a URL. Unlike apps, most websites are automatically indexed by search engines, so if a user seeks information about any given library on their mobile device they will arrive at the library's website instead of the app.

The "coolness factor" of apps and the increase of discoverability provided by app stores are two arguments in fa- vor of the development of apps according to Iglesias and Meesangnil (2011), Wisniewski (2011) and Wong (2012). However, this is difficult to believe, because the most significant app stores, Apple's App Store and Google Play, have both surpassed 1.5 million applications each. The obvious resulting dilemma is how an app can stand out among so many others. According to Wong's experience with HKBUtube from Hong Kong Baptist University, apps do not highlight when they are on an app store, but if they are also recommended by the store (Wong, 2012).

Among the topics addressed in a mobile application bibliography we found creation experiences (Johnstone, 2011; Clark, 2012; La-Counte, 2012; Merlo-Vega, 2012; Pu et al., 2015), content and services (Bomhold, 2015), compilations of the number of libraries with their own apps (Canuel; Crichton, 2015; Torres-Pérez; Méndez-Rodríguez; Orduña-Malea, 2016), app selection for certain purposes (Besara, 2012), and how to determine which app is the most suitable for a particular library service (Henning, 2014; Oberlies, 2015). The bibliography on mobile websites is also extensive and deals with similar topics, although in this case with a focus on how to choose the features and content for the mobile version, whether by meeting the users' demands (Wilson; McCarthy, 2010; Rempel; Bridges, 2013) or by analyzing the content and features included on the website, (Aldrich, 2010; Canuel; Crichton, 2011).

Despite some publications that have analyzed usage data of libraries' apps and mobile websites (Haefele, 2013; Pulgar-Vernalte; Maniega-Legarda, 2014), they are rarely compared. One of the few previous instances was authored by Wong (2012), who compared the number of views on his app HKUTube and the views in a similar website, different than the main library website. Unlike previous research, this paper offers real comparative data between the usage of the mobile-adapted version of the library of the University of Salamanca's website and its app, as well as between PC users and mobile-device users. The conclusions that result will help university libraries decide whether to create an app or design a mobile website.

\subsection{Background}

The University of Salamanca (USAL) is the oldest functioning university in Spain. It was founded in 1218 and currently hosts a university community of 36,035 users; 33,000 of whom are students and 2,400 are professors and researchers, while administrative and services personnel make up the rest. USAL offers over 65 bachelor's degrees and 70 official university master's as well as several multidisciplinary certificates. Its most renowned research areas are biomedical and human sciences. Library acquisitions and technical processes are organized centrally, while its services are decentralized and available at 25 locations (thematic and college libraries).

Its mobile app was developed so that users could access library services and resources from handheld smart devices; after analyzing the increasing use of mobile devices to access web resources, the creation of a library app and a mobile web were approved. The app was also regarded as a marketing asset, since the use of apps was booming and 
there were no library apps in Spain or any Spanish-speaking country.

The adoption of smartphone use in the Spanish market soars higher than the European average, so libraries feel pressed to adapt content to these devices. According to ComScore data, $83 \%$ of mobile phone users above 13 years of age had a smartphone in 2014 (eMarketer, 2014) and almost nine out of ten smartphones sold between June and August 2015 ran on Android. This tendency has remained above $80 \%$ since 2012 , as sales of iOS systems comprised $6.2 \%$ of the market, while those of Windows Phone, $3.2 \%{ }^{1}$

The percentage of users who accessed the Internet on a smartphone in 2014 (91.8\%) outnumbered desktop PC (72.4\%) or laptop (76.9\%) users. It is crucial to highlight that more than half of the total number of Internet users relied on a tablet to browse the Internet (54.7\%) (AIMC, 2017).

\section{Research question}

Many librarians are wondering whether they should create an app or a mobile version of their website and they want to know the significant differences of each based on use. Although apps are an attractive way to present content and services, libraries have been essentially offering the same functionality as their websites, failing to take advantage of the host of features a mobile app allows for. Some libraries have developed both a mobile website and an app, which seems to indicate there is no clear understanding of which works best. We use the term "mobile website" to refer to a website which has been designed for access on a mobile device, regardless of what technique has been utilized in its design (responsive web design, different webpages for mobile users, or others).

In order to provide an answer to these questions, we analyzed the usage data of Biblio USAL and that of its mobile web counterpart.

The case of the Library of the University of Salamanca is especially significant because Biblio USAL was the first ever library app in Spain. It has been available on Apple's App Store since November 10, 2011 and on Android Market (now Google Play) since December 9, 2011. There has also been a mobile version of its website, ${ }^{2}$ available since February 14 , 2013 (Merlo-Vega, 2012).

\section{Methodology}

The tool used to extract usage data from both our mobile website and app was Google Analytics. As we used the same tool for both, we were able to handle homogenous and comparable data. Google Analytics is an excellent resource to obtain site traffic data. The site is monitored by Google after adding a tracking code to the website's source code, generating data about the page requested, such as number of visits, equipment and operating systems used to browse the site, the user's country of origin, or the path followed to arrive at the site. Due to the popularity of Google accounts, this system includes some information about the site's users, such as gender or age. Google Analytics is currently the most widely used system to report on a site's traffic.
Because our app is hybrid -its content is hosted in a website-, Google Analytics can be used to extract usage measurements. Since the features of the app are only informative, there are no other functionalities to be measured. Data was gathered starting on July 18, 2011, when the tool was first used at USAL, and the periods established for the current study coincide with each school year, i.e., each period covers September $1^{\text {st }}$ to the next August $31^{\text {st }}$. We obtained four analysis periods, corresponding to the school years 20112012, 2012-2013, 2013-2014, and 2014-2015.

The data extracted by Google Analytics was divided as follows:

- Sessions, defined by Google Analytics as "a group of interactions that take place on your website within a given time frame. [...] A visit can be defined as the element which encompasses a visitor's actions on your website. You can think of a session as the container for the actions a user takes on your site". According to Kaushik (2010), a session reflects that someone has accessed a website and has spent some time there.

- Web pages seen per session. The number of pages a user browses during a session.

- Average duration of a session. The time that elapses since a user opens a session until he/she closes it.

- Bounce rate. As explained by Google Analytics, bounce rate is the percentage of single page visits (or web sessions), i.e. when a person leaves your website from the landing page without browsing any further. It is an indicator of the interest the website generates.

Even though the app is available on Android devices, Google Analytics only registers visits to the app on iOS devices, so we must bear in mind that our data is partial and only represents a percentage of the total number of visits. As a counterbalance to this limitation, the cumulative number of times the app has been downloaded since its creation (data provided by Google Play and App Store) has been analyzed, but the scope this information offers is fragmented, since Google Play and App Store provide download data differently. Google Play provides the number of active installations on Android devices, whereas App Store supplies the total number of downloads, active or not, on devices running iOS. Also of interest is the fact that Google does not provide a monthly number of downloads, but a cumulative total sum.

The number of times other Spanish libraries' apps have been downloaded (publicly available on Google Play) has also been analyzed for comparison purposes. This data is given as a interval, so an exact number of downloads is only available for the Android version of the app.

Several articles have been published presenting mobile web and app usage data, but none have featured a compared analysis to date.

\section{Results and discussion}

\subsection{Access to the Library's web via mobile devices}

The percentage of sessions on the Library of USAL's website on mobile devices has gradually grown in the last four academic school years and amounted to $14.6 \%$ of the total number of visits $(431,268)$ in 2014-2015, while in 2011-2012 it was $5.3 \%$ of the total $(291,354)$. This growth can be attri- 
buted to an increase in the use of smartphones, while the number of sessions on tablet PCs has been steadier. It is conceivable to expect that this upward trend will continue in the following years. If $91.8 \%$ of Spanish users access the Internet on a smartphone and $54.7 \%$ on a tablet, there is without doubt ample margin for further growth. There is no evidence significant enough to claim that this growth has gained momentum due to the release of the mobile website. However, it can be argued that the mobile web made its contribution over time and this growth has gone further than could have been initially expected. The average number of sessions on the web per library user on smartphones would be 1.4 , on tablets 0.4 and on desktop computers 10.2.

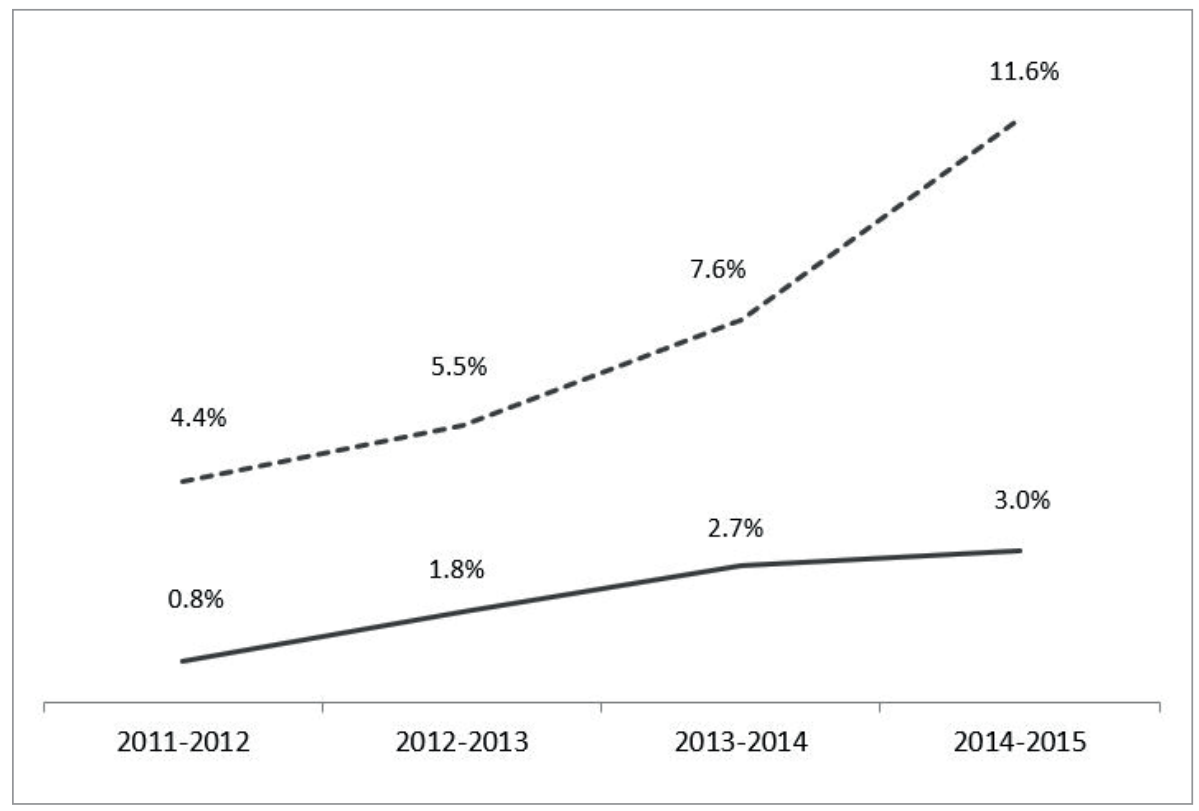

Chart 1. Percentage of sessions on smartphones (dotted line) and tablets (solid line) on bibliotecas.usal.es

The website is used differently on smartphones, tablets, and personal computers. Smartphone users browse the fewest pages, an average of 2.25 per session in the school year 2014-2015, in contrast with those viewed by PC users, 2.60 (15.6\% more than on smartphones). Tablet users browse the highest number of pages per session, 2.78.

The shortest sessions are those opened by smartphone users. The average duration of a session on a personal computer during 2014-2015 was 3 minutes and 9 seconds, while on a tablet it decreased to 1 minute and 45 seconds and on a smartphone, to 1 minute and 19 seconds. This data must be taken into account when discussing content organization, since it reveals that smartphone users are less inclined to spend time browsing the site.

The bounce rate for bibliotecas.usal.es reached $57.7 \%$ in 2014-2015. The fact that its catalog is located in a different directory could account for how high this percentage is, and, as Farney and McHale (2013) explain, Google Analytics does not feature the possibility of analyzing outbound links. This bounce rate is still quite high in sessions opened on smartphones (59.8\%) and tablets (48.3\%).

The differences between Android and $i O S$, the most commonly used operating systems to access USAL's Library online on mobile devices, are minimal. During the previous school year, 2014-2015, the number of pages visited per session, average duration, and bounce rate were very similar for both.

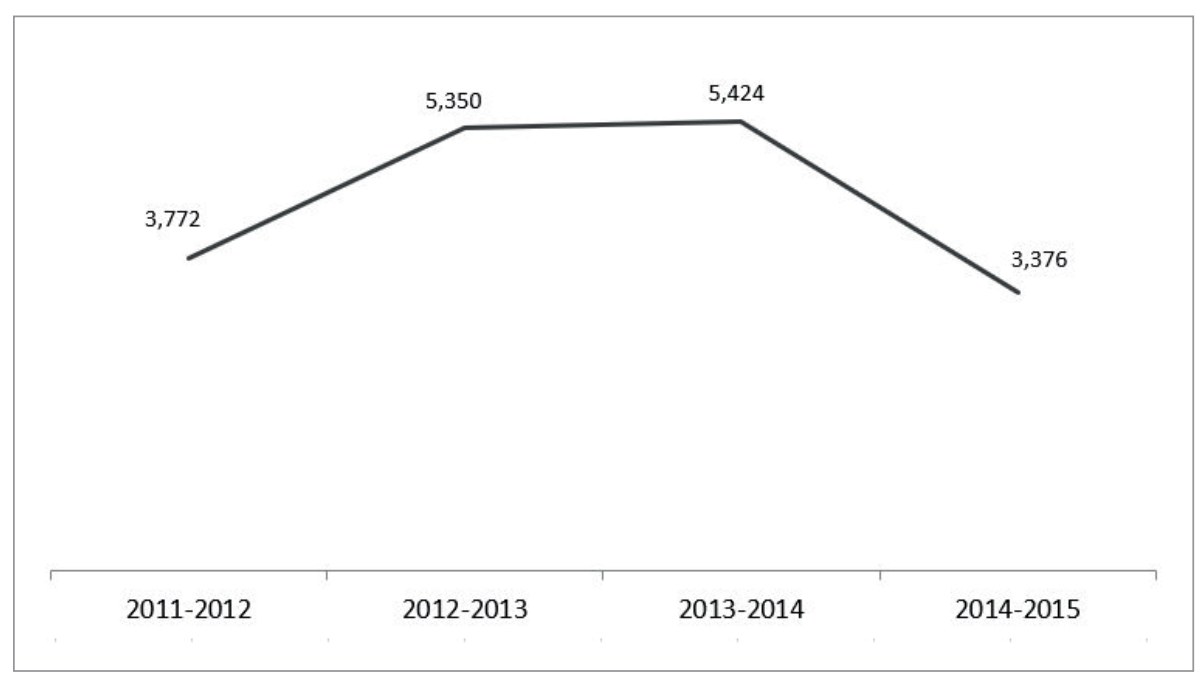

Chart 2. Number of sessions per school year registered on Biblio USAL on mobile devices running iOS.

\subsection{Biblio USAL}

Biblio USAL was launched in November 2011 and updated to a second version in January 2013, coinciding with the mobile web version of bibliotecas.usal.es. This first version put at the user's disposal informative content and catalog browsing features common in library apps. The version released in 2013 included bibliographical management and document reservation. The third version will be oriented toward search engine features, user authentication, and digital content reading on the app itself. Also in January 2013, bibliotecas.usal.es was adapted to a mobile web version.

Its usage data shows how the app has evolved. There were 3,376 sessions registered on iOS devices in the last school year analyzed (2014-2015), 37.8\% fewer than the 5,424 registered in the previous one, in contrast with the increase recorded since the app's launch until present. Contrary to the app, the website registered 20,855 sessions on iOS devices alone, a third of the total of the sessions on handheld 
devices. A lack of promotion may explain the decline in the number of app sessions in the last school year analyzed. Throughout 20112013, several campaigns promoting Biblio USAL were organized, and had a significant impact on how often the app was used (chart 3). These campaigns were conducted as follows:

- In November 2011 Biblio USAL was released and 535 visits were registered, $170.6 \%$ more than the average for the academic year 2011-2012, which 314 visits per month.

- In January 2012, 463 visits were registered, $147.6 \%$ more than the average, due to a new promotional campaign.

- In May 2012 “Mi biblioteca”, a professional magazine, published an article about Biblio USAL (Merlo-Vega, 2012). That month the number of visits increased to $752,239.7 \%$ above that school year's average.

- In October 2012 the app was discussed on a local radio program and the number of visits that same month was 607. The average for $2012-2013$ was 440 sessions per month, an increase of $137.9 \%$.

- In January 2013 the second version of Biblio USAL was launched, which had an impact on the number of visits, increasing $172.2 \%$ of the school year's average.

- A social media campaign was organized at the end of February 2013, resulting in 663 visits, $150.6 \%$ more than the school year's average.

- In May 2013 the app was discussed in a professional conference during the Jornadas Españolas de Documentación. 506 visits were registered, $115.0 \%$ more than the monthly average.

Just one promotional campaign, run in June 2012, did not correspond with a significant increase in the number of visits.

In 2014-2015 the average duration of a session on the app was 3 minutes and 5 seconds on iOS devices, whereas the average duration of the sessions on the website opened on iOS devices was 1 minute and 14 seconds. All of which co- mes to show that users spend more time browsing its content. When considering the evolution of the app since it was launched, we can see a decrease in the average duration of the sessions opened on the app, as in 2011-2012 when it reached 10 minutes and 16 seconds while in 2013-2014, 5 minutes and 52 seconds.

The number of pages browsed per session on the app is also higher, with an average of 7.8 pages on smartphones and tablets versus 2.32 pages browsed on the mobile web, also on iOS devices. Finally, the bounce rate is significantly lower in the app than on the website, just $0.88 \%$ on smartphones and $0.68 \%$ on tablets in the previous school year and $56.09 \%$ on the mobile web on iOS devices.

Biblio USAL has been downloaded 4,402 times on the App Store since its release in 2011 and remains installed on 878 Android devices (see table 1). We have to take into account that these figures represent different concepts, the one provided by App Store shows the total number of downloads while Google Play's shows how many downloads remain installed (19.8\%). This percentage lets us conclude that the app has been downloaded a total of 8,836 times, 4,434 on Android devices and 4,402 on Apple's devices.

The breakdown by percentage of downloads on iOS devices is $35.9 \%$ on $\mathrm{iPad}, \mathbf{5 3 . 2 \%}$ on iPhone, and $6.1 \%$ on iPod

Table 1. Number of downloads of Biblio USAL from the App Store and active installations on Android devices.

\begin{tabular}{|c|c|}
\hline \multicolumn{2}{|c|}{ App Store downloads } \\
\hline Period & Downloads \\
\hline $2011-2012$ & 1,480 \\
\hline $2012-2013$ & 1,500 \\
\hline $2013-2014$ & 877 \\
\hline $2014-2015$ & 545 \\
\hline Total & 4,402 \\
\hline
\end{tabular}

\begin{tabular}{|c|c|}
\hline \multicolumn{2}{|c|}{ Active installations on Android } \\
\hline Period & Installations \\
\hline $2011-2012$ & 284 \\
\hline $2012-2013$ & 637 \\
\hline $2013-2014$ & 845 \\
\hline $2014-2015$ & 878 \\
\hline
\end{tabular}


Touch. The remaining $4.9 \%$ correspond to devices we have not been able to identify. On Android devices, only $20.2 \%$ of the active installations correspond to tablets.

\subsection{Other library apps in Spain}

If we compare the number of times Biblio USAL has been downloaded on Android devices with that of other Spanish libraries' applications, USAL's app is in a similar range of cumulative downloads, or even surpasses the others. On the other hand, we have to take into account the fact that Android devices take the largest share of the market in Spain as $89.9 \%$ of the smartphones sold in Spain in 2015 featured this operating system and it is also frequent used on tablets.

When dividing the app downloading data of Spanish libraries on Android devices by the number of users of each library (table 2), we find very unbalanced results. Thus, more recently created apps have a low range of cumulative downloads, which indicates that they are reaching less than $5 \%$ of their users, some even less than $1 \%$. Older apps, however, obtain better penetration rates among their users.

Biblio USAL has been downloaded 4,402 times on iOS devices, which represents $12.2 \%$ of users. If this percentage is added to the percentage of downloads on Android, it could be said that the app has been downloaded by $15.0 \%$ to $26.1 \%$ of the users. Conversely, taking into account the number of active downloads, it is conceivable that the exact number lies closer to $15.0 \%$.

In Spain the applications for large networks of public libraries stand below the level of university libraries. In one representative case, the Biblioteques of Barcelona (BibliosBCN), app users comprise between $1.1 \%$ and $5.4 \%$ of the total number of library users. The significant difference may be due to the type of user each library attracts: public libraries have a more diverse population while university li-

Table 3. Number of downloads of public library apps in Spain by number of users. Data collected on October 9, 2015.

\begin{tabular}{|l|r|r|r|r|r|r|}
\cline { 4 - 7 } & \multirow{2}{*}{ Date of creation } & \multirow{2}{*}{$\begin{array}{c}\text { Library } \\
\text { users }\end{array}$} & \multicolumn{3}{|c|}{ Downloads (cumulative) $^{6}$} \\
\cline { 5 - 7 } & & Below & $\%$ & Above & $\%$ \\
\hline BibliosBCN & $04 / 29 / 2013$ & 924,178 & 10,000 & 1.1 & 50,000 & 5.4 \\
\hline Bibliotecas de Navarra & $12 / 06 / 2013$ & 238,980 & 1,000 & 0.4 & 5,000 & 2.1 \\
\hline Biblio JCyL & $09 / 14 / 2014$ & $1,099,566$ & 1,000 & 0.1 & 5,000 & 0.5 \\
\hline BibliotequesXBM & $11 / 16 / 2014$ & $2,623,832$ & 10,000 & 0.4 & 50,000 & 1.9 \\
\hline Bibliotecas de La Rioja & $11 / 17 / 2014$ & 83,029 & 10 & 0 & 50 & 0.1 \\
\hline Liburutegiak & $02 / 26 / 2015$ & 570,000 & 100 & 0 & 500 & 0 \\
\hline
\end{tabular}

braries attract a younger demographic, a population whose ownership of mobile devices is more widespread.

It seems clear that not every library user can be expected to install their library's application, but the percentages extracted up to this point seem extremely low, even when it comes to applications that have been available for a long period of time. The number of downloads is data that goes no further, since it does not let us know how many people still have it installed on their devices or how many users actually use it, as this data is only available to the app's developer.

\section{Conclusions and further work}

Usage data gathered by the Library of the University of Salamanca shows a preference for its mobile website rather than its app when it comes to users of iOS smartphones and tablets - the number of sessions on the mobile website is six times higher than on the app. However, those who make use of Biblio USAL do so more intensively: more pages are visited per session, the sessions are longer, and the bounce rate is scant.

This data also suggests that, in some cases, those who access the website do so in search of specific information, such as opening hours, since they visit only a few pages and do not browse the website. We can therefore conclude that those who choose the app over the website form a small group of intensive library users, because they spend more time visiting the website and view more pages during each session.

Another crucial question regarding apps is their popularization. In previous research, it has been confirmed that a library's website, or the institution a library was represented by, does not include a link to their apps in $32.9 \%$ of the cases. Of those apps that have been linked, more than half (57.1\%) were not linked on the main webpage, but on an intermediary page which gave information about the app - something that forces the user to click 
at least twice before downloading it- or from another page within the website (Arroyo-Vázquez, 2015).

Contrary to what happened with the website, where access on mobile devices was on the increase, the usage tendency of Biblio USAL has been been getting progressively lower, as shown by the number of downloads and sessions. In this case, constant promotion has proven necessary to grow the number of sessions for an app.

Judging by the number of downloads of other native applications of libraries in Spain, they are not achieving the success that was expected of them, especially apps for public libraries. The experience of Biblio USAL proves that these apps are mainly used by more intensive users. This issue makes us question whether the investment resources in the development of an app is worth it, given how little it is actually used, when a mobile website can offer the same service. The obvious answer seems to be negative, or that at least an app of this kind must be a complement to a website, an additional service for the more intensive library users. We would recommend at this time that libraries prioritize investment in a solid web presence.

We cannot forget to mention that we are talking about native applications that reproduce, practically verbatim, the content a website offers, apps that could be dubbed «first generation library apps». There are several applications in existence that allow for more direct transactions. An example is NLB Mobile, the app of the National Library Board Singapore, which lets the user complete transactions (loans and renewals) by scanning the book's barcode, as well as configure several user profiles and reservations, search the catalog, locate the nearest library, and obtain other basic information such as opening times, location address, and forthcoming events. This type of second generation app delivers practical services to the users, facilitating their relationship with the library together with the provision of information.

There are already concerns regarding lack of visibility on App Stores. In many cases, users reach the content they are looking for through a search engine, and apps simply cannot compete with the powerful and widespread use of search engines. Although efforts toward deep linking are already being made (which would allow us to link to specific content within an app) and Google has let apps index their content on mobile devices since May 2015 (Wald, 2015), working with deep linking is still infrequent.

As a general conclusion we can say that, when accessing the same content, the users would rather work with the mobile web than the app. This research suggest that library apps are of interest for users when they offer features exclusive to mobile devices. This is the reason why the libraries of the University of Salamanca have developed a new version of their app, Biblio USAL 3, which allows users to access information resources using native technologies for document searching, identification of authorized users, and digital reading, all on the same device.

Biblio USAL 3, the next version of the app, is an outcome based on what was learned from the first years of the app. The data suggests that a library app is only useful if the user can perform operations on it that are unavailable on the mobile web and are created exclusively for mobile devices. This is the reason why its third iteration will focus on three areas: access to every resource, single authentication protocol, and support for the reading of digital content, all on the same device. Access will be processed through Worldcat Discovery API, since the University of Salamanca works with OCLC services. This API will allow access to every information resource USAL has acquired and subscribes to. The second step is user authentication and access to authorized resources. The app will utilize idUSAL, a federated authentication system based on CAS and Sibboleth, which will allow the user to access the system just using his/her email address and password. Once the user has been identified, the desired resources will be accessed via EZproxy. Finally, the app will connect with whatever reading apps are installed on the user's device, including those that allow Adobe DRM protected content, as USAL has a digital lending platform with e-books available on the library's Discovery.

Usage data of this new generation app should be contrasted with the data offered in this article in order to establish whether there is a future for apps in library services or if all development should be focused on mobile web development.

In order to complement the results of this study, we suggest conducting a survey among our users in the future to see if these upgrades have met their needs. Their comments on Biblio USAL 3 and the mobile web would enable us to make any necessary adjustments, inclusion of features, and improvements that might enhance future versions of our app. Because the data we have presented in this study belongs to a specific experience and location, having access to similar usage data (very briefly dealt with in this article due to the glaring absence of it) from other libraries would strengthen the findings. In order to accomplish this, we would like to invite any other libraries to share usage data obtained from their apps and/or mobile website.

\section{Notes}

1. Kantar Worldpanel. "Smartphone OS sales market share." http://www.kantarworldpanel.com/global/smartphone-osmarket-share

\section{Libraries at the University of Salamanca http://bibliotecas.usal.es}

3. Source: Rebiun. Indicadores de las bibliotecas, 2014. http://estadisticas.rebiun.org/cuestionarios/indicadores/ indicadores_main.asp\#

\section{Data retrieved from Google Play.}

5. Source: statistics published by each library network.

6. Data retrieved from Google Play.

\section{References}

AIMC (2015). Navegantes en la Red. $17^{a}$ Encuesta AIMC a usuarios de internet.

https://goo.gl/svqWo1

Aldrich, Alan W. (2010). "Universities and libraries move to the mobile web". Educause quarterly, v. 10, n. 2. http://er.educause.edu/articles/2010/6/universities-andlibraries-move-to-the-mobile-web 
Arroyo-Vázquez, Natalia (2015). Sitios web y aplicaciones nativas para móviles en bibliotecas. El caso de la Biblioteca de la Universidad de Salamanca. PhD Diss., Salamanca (Spain): University of Salamanca.

https://gredos.usal.es/jspui/bitstream/10366/128006/1/ DBD_ArroyoVazquezN_AplicacionesBibliotecas.pdf

Besara, Rachel (2012). "Apps for assessment: A starting point". The reference librarian, v. 53, n. 3, pp. 304-309.

http://diginole.lib.fsu.edu/is/andora/object/fsu:252675/ datastream/PDF/view

https://doi.org/10.1080/02763877.2012.678791

Bomhold, Catharine (2015). "Research and discovery functions in mobile academic libraries: Are university libraries serving mobile researchers?". Library hi tech, v. 33, n. 1, pp. 32-40. https://goo.gl/qx6aea

https://doi.org/10.1108/LHT-09-2014-0084

Bridges, Laurie; Rempel, Hannah-Gascho; Griggs, Kimberly (2010). "Making the case for a fully mobile library web site: From floor maps to the catalog". Reference services review, v. 38, n. 2, pp. 309-320.

http://ir.library.oregonstate.edu/xm/ui/handle/1957/16437 https://doi.org/10.1108/00907321011045061

Canuel, Robin; Crichton, Chad (2011). "Canadian academic libraries and the mobile web". New library world, v. 112, n. 3/4, pp. 107-120.

https://tspace.library.utoronto.ca/handle/1807/33920 https://doi.org/10.1108/03074801111117014

Canuel, Robin; Crichton, Chad (2015). “Leveraging apps for research and learning: A survey of Canadian academic libraries". Library hi tech, v. 33, n. 1, pp. 2-14.

https://goo.gl/1j8tzc

https://doi.org/10.1108/LHT-12-2014-0115

Clark, Jason A. (2012). Building mobile library applications. London: Facet Publishing. ISBN: 9781555708238

eMarketer (2014). "Smartphones rule in Spain". eMarketer, November 10.

http://www.emarketer.com/Article/Smartphones-RuleSpain/1011558

Farney, Tabatha; McHale, Nina (2013). Web analytics strategies for information professionals. Chicago: ALA TechSource. ISBN: 9781555708979

Haefele, Chad (2013). "Mobile catalogs". En: Peters, Thomas A.; Bell, Lori (eds.). The handheld library: Mobile technology and the librarian. California: Libraries Unlimited, pp. 95-108. ISBN: 9781610693004

Henning, Nicole (2014). Selecting and evaluating the best mobile apps for library services. Library technology reports, v. 50, n. 8. ISBN: 9780838959428

Iglesias, Edward; Meesangnil, Wittawat (2011). "Mobile website development: From site to app". Bulletin of the American Society for Information Science and Technology, v. 38, n. 1, pp. 18-23.

https://doi.org/10.1002/bult.2011.1720380108

Johnstone, Brian T. (2011). “Boopsie and librarians: Connec- ting mobile learners and the library". Library hi tech news, v. 28, n. 4, pp. 18-21.

https://goo.gl/ANEQ2j

https://doi.org/10.1108/07419051111154776

Kaushik, Avinash (2010). Web analytics 2.0: The art of online accountability and science of customer centricity. Indianapolis: Wiley. ISBN: 9780470529393

La-Counte, Scott (2012). Going mobile: Developing apps for your library using basic html programming. Chicago: ALA Editions. ISBN: 9780838911297

Merlo-Vega, José-Antonio (2012). “Biblio USAL, la primera aplicación de bibliotecas nativa para dispositivos móviles realizada en España". Mi biblioteca, v. 8, n. 29, pp. 54-60.

Nielsen, Jakob; Budiu, Raluca (2012). Mobile usability. Berkeley: New Riders Press. ISBN: 9780321884480

Oberlies, Mary K. (2015). "Techniques for finding and evaluating great library apps". Online searcher, v. 39, n. 2, pp. 50-53. http://pqasb.pqarchiver.com/infotoday/doc/1691942105.html

Pu, Ying-Hung; Chiu, Po-Sheng; Chen, Tzung-Shi; Huang, Yueh-Min (2015). "The design and implementation of a mobile library app system". Library hi tech, v. 33, n. 1, pp. 15-31. https://doi.org/10.1108/LHT-10-2014-0100

Pulgar-Vernalte, Francisca; Maniega-Legarda, David (2014). “'Liburutegiak' app: la biblioteca en la palma de tu mano”. En: $80^{\text {th }}$ IFLA General conference and assembly, August 16-22, Lyon. http://eprints.rclis.org/23517

Rempel, Hannah-Gascho; Bridges, Laurie (2013). "That was then, this is now: Replacing the mobile-optimized site with responsive design". Information technology \& libraries, v. 32, n. 4, pp. 8-24. http://ejournals.bc.edu/ojs/index.php/ital/article/view/4636

Serrano, Jordi (2014). “¿Mobile o app? ¿Ésta es la cuestión?”. Blok de BiD, December 17th.

http://www.ub.edu/blokdebid/es/node/560

Torres-Pérez, Paula; Méndez-Rodríguez, Eva; Orduña-Malea, Enrique (2016). "Mobile web adoption in top ranked university libraries: A preliminary study". The journal of academic librarianship, v. 42, n. 4, pp. 329-339.

https://orff.uc3m.es/handle/10016/25217

https://doi.org/10.1016/j.acalib.2016.05.011

Wald, Eli (2015). "Surfacing content from iOS apps in Google Search". Google developers blog, May $27^{\text {th }}$. https://goo.gl/BZhc7B

Wilson, Sally; McCarthy, Graham (2010). "The mobile university: from the library to the campus". Reference services review, v. 38, n. 2, pp. 214-232. https://doi.org/10.1108/00907321011044990

Wisniewski, Jeff (2011). "Mobile that works for your library". Online, v. 35, n. 1, pp. 54-57.

Wong, Shun-Han-Rebekah (2012). "Which platform do our users prefer: website or mobile app?". Reference services review, v. 40, n. 1, pp. 103-115.

https://goo.gl/CmxMai

https://doi.org/10.1108/00907321211203667 